\title{
Investigation of Surface Scaling, Optical and Microwave Dielectric Studies of Bi0.5Na0.5TiO3 thin Films
}

\section{Srinivas Pattipaka}

IIT Guwahati

Pamu D ( $\sim$ pamu@iitg.ernet.in )

Indian Institute of Technology Guwahati https://orcid.org/0000-0002-0834-8461

\section{Pundareekam Goud J}

University of Hyderabad

James Raju K C

University of Hyderabad

\section{Gbinda Pradhan}

IIT Guwahati

\section{Sridhar V}

V R Siddhartha Engineering College

\section{Research Article}

Keywords: Pulsed laser deposition, Oxygen partial pressure, Scaling theory, Optical properties, Microwave dielectric properties

Posted Date: March 18th, 2021

DOl: https://doi.org/10.21203/rs.3.rs-332237/v1

License: (9) This work is licensed under a Creative Commons Attribution 4.0 International License. Read Full License

Version of Record: A version of this preprint was published at Journal of Materials Science: Materials in Electronics on October 9th, 2021. See the published version at https://doi.org/10.1007/s10854-02106970-8. 


\title{
Investigation of surface scaling, optical and microwave dielectric studies of $\mathrm{Bi}_{0.5} \mathrm{Na}_{0.5} \mathrm{TiO}_{3}$ thin films
}

\author{
Srinivas Pattipaka, ${ }^{1,2}$ Pamu Dobbidi, ${ }^{1, *}$ Pundareekam Goud J, ${ }^{3}$ James Raju K C, ${ }^{3}$ Gobinda \\ Pradhan, ${ }^{1}$ and Sridhar V, ${ }^{4}$ \\ ${ }^{1}$ Department of Physics, Indian Institute of Technology Guwahati, Guwahati 781039, India. \\ ${ }^{2}$ Department of Freshman Engineering, Vardhaman College of Engineering, Shamshabad, \\ Hyderabad 501218, India. \\ ${ }^{3}$ School of Physics, University of Hyderabad, Hyderabad, Telangana 500046, India. \\ ${ }^{4}$ Department of Mechanical Engineering, V R Siddhartha Engineering College, Vijayawada \\ 520007, India.
}

\begin{abstract}
Herein, we have investigated the optical and microwave dielectric properties of $\mathrm{Bi}_{0.5} \mathrm{Na}_{0.5} \mathrm{TiO}_{3}(\mathrm{BNT})$ thin films grown under different oxygen pressure $\left(P_{O 2}\right)$ using pulsed laser deposition (PLD) technique. The X-ray diffraction measurements confirms the single phase of BNT along with secondary phase and further reduction in secondary phase and increase in BNT phase with $\mathrm{P}_{\mathrm{O} 2}$, signifies the close relation between the crystal structure and oxygen content. The shift of Raman-active TO1, TO2 and TO3 modes towards higher wavelengths and increase in mode intensity with $P_{O 2}$ indicating the films degree of crystallinity. The local roughness $\left(\alpha_{\mathrm{loc}}\right)$ of all films obtained as $\sim 0.85$, and the interface width $(\omega)$ and lateral correlation length $(\xi)$ of films varies with $P_{O 2}$. Also, the films exhibit the increase in refractive index and reduction in optical bandgap of due to improvement in crystallinity and reduction in the oxygen vacancies. The microwave dielectric properties show a strong $P_{O 2}$ depends with higher dielectric constant $\left(\varepsilon_{r}=336\right)$ with lower loss $(\tan \delta=0.0093)$ at $5 \mathrm{GHz}$ which show the potential applications in high frequency devices.
\end{abstract}


Keywords: Pulsed laser deposition; Oxygen partial pressure, Scaling theory; Optical properties; Microwave dielectric properties

\section{Introduction}

The study of Ferroelectric perovskite oxides in condensed matter research has renewed enamours scientific interest owing to their technological applications such as capacitors with tunable capacitance, ferroelectric non-volatile dynamic random-access memory (DRAM), radio-frequency identification (RFID) cards, piezoelectric sensors and actuators, and pyroelectric devices, etc. [1-4]. Particularly, the lead-based ferroelectric materials like $\mathrm{Pb}(\mathrm{ZrTi}) \mathrm{O}_{3}(\mathrm{PZT}), \mathrm{Pb}(\mathrm{ZnNb}) \mathrm{O}_{3}(\mathrm{PZN}), \mathrm{Pb}(\mathrm{MgNb}) \mathrm{O}_{3}(\mathrm{PMN}), \mathrm{Pb}(\mathrm{NiNb})(\mathrm{PNN})$ have been receiving much attention due to their excellent dielectric, ferroelectric, piezoelectric and pyroelectric properties for the above mentioned applications[5-9]. In the last decade, many research efforts on the lead-free piezoelectric materials such as $\mathrm{BaTiO}_{3}(\mathrm{BT}),(\mathrm{Ba}, \mathrm{Zr}) \mathrm{TiO}_{3}$ (BZT), (Ba,Ca) $\mathrm{TiO}_{3}(\mathrm{BCT}),(\mathrm{Ba}, \mathrm{Sr}) \mathrm{TiO}_{3}(\mathrm{BST}), \quad\left(\mathrm{Bi}_{0.5} \mathrm{Na}_{0.5}\right) \mathrm{TiO}_{3}(\mathrm{BNT}),\left(\mathrm{Bi}_{0.5} \mathrm{~K}_{0.5}\right) \mathrm{TiO}_{3}$ (BKT) and $\left(\mathrm{K}_{0.5} \mathrm{Na}_{0.5}\right) \mathrm{NbO}_{3}(\mathrm{KNN})$ replace the PZT because of its toxicity [10-16]. The rapid progress in the BNT and its solid solutions was identified them as high-performance lead-free ferroelectric and piezoelectric materials.

It was firstly discovered by Smolenskii et al., is an $\mathrm{ABO}_{3}$ complex perovskite-structured material with random distribution of $\mathrm{Bi}^{+3}$ and $\mathrm{Na}^{+}$ions at $\mathrm{A}$-site [17]. At room temperature (RT), it has a rhombohedral ferroelectric perovskite with R3c space group, which exhibits high Curie temperature $\left(T_{C} \sim 320{ }^{\circ} \mathrm{C}\right)$, high dielectric constant $\left(\varepsilon_{r}\right) \sim 694 @ 1 \mathrm{kHz}$ and low dielectric loss $(\tan \delta) \sim 0.046$, large remnant polarization $(P r) \sim 38 \mu \mathrm{C} / \mathrm{cm}^{2}$ at high coercive field $\sim 73$ $\mathrm{kV} / \mathrm{cm}$ resultant poor in piezoelectric coefficient $\left(d_{33}\right) \sim 80 \mathrm{pC} / \mathrm{N}$ because of polling difficulties $[18-20]$

It is very essential to clarify the physical properties to fabricate BNT suitable in electrical and optical devices for electrical and optical response. The thin film materials can be expected 
to produce good sensitivity, quicker response, and cheaper as compared to that of bulk ceramics. Therefore, a detail study on BNT thin films is absolutely necessary for the fabrication and characterization of electrical and optical properties [21,22]. To deposit a single phase of BNT, maintain its stoichiometry and better crystallinity in the thin film is a challenging task due to the volatile nature of the elements in the present composition. The volatilization of $\mathrm{Bi}$ and $\mathrm{Na}$ are leading to the formation of secondary phases, oxygen deficiencies, and higher leakage currents resulting in weak dielectric, ferroelectric and piezoelectric properties. However, to the best of the author's knowledge, there are very few reports available on BNT thin films. In perovskite oxide thin films, the oxygen partial pressure is one of the critical parameters which plays an important role to controlling the growth, high quality of crystalline thin films with optimum $P_{O 2}$. [23-25] Therefore, the underlying benefits of PLD motivated us to deposit complex oxide BNT films with an excess of $\mathrm{Bi}$ and $\mathrm{Na}$ with $5 \mathrm{~mol} \%$ and to investigate the effect of oxygen partial pressure on structural, morphological, optical and electric properties systematically.

The surface morphology, microstructure, and roughness of thin films play an important role and are strongly dependent on the deposition process and growth conditions such as deposition time (thickness), substrate temperature, oxygen pressure, and etc. The film surface morphology can also control the optical and electrical properties, which affect device performance. Therefore, it is essential to understand the growth mechanism of the deposited thin films. In recent years, the growth behavior of various thin film systems was reported for different inorganic materials (metals, semiconductors, and perovskite oxides) [26-28]. The theoretical concepts have been developed to study the growth dynamics of films by atomic force microscope (AFM) measurements. The scaling theory is used to understand the growth dynamics to evaluate the statistical properties from surface morphology of films. In the past years, many theoretical models were established to study the growth mechanism of films to a set of scaling exponents [29-31]. However, there are no 
reports available on the growth mechanism of PLD deposited BNT films using scaling theory and is motivated to pursue this study. In this work, the surface scaling studies of deposited BNT thin films by PLD as a function of oxygen partial pressure are investigated in detail. The microwave dielectric properties of thin films have been widely reported for microwave communication, phase shifters, filters and resonators[32]. Nevertheless, there are limited studies available involving with microwave dielectric properties of BNT films, which suggested to study the influence of $\mathrm{O}_{2}$ partial pressure on microwave dielectric properties of $\mathrm{BNT}$ thin films systematically.

\section{Experimental Procedures}

Home-made $\mathrm{Bi}_{0.5} \mathrm{Na}_{0.5} \mathrm{TiO}_{3}$ (BNT) ceramic target was prepared by a solid-state reaction method. The $\mathrm{Bi}_{2} \mathrm{O}_{3}, \mathrm{Na}_{2} \mathrm{CO}_{3}$ and $\mathrm{TiO}_{2}$ powders (M/s Sigma-Aldrich, USA, 99.99\%) have been used as initial materials. The excess of $\mathrm{Bi}_{2} \mathrm{O}_{3}$ and $\mathrm{Na}_{2} \mathrm{CO}_{3}$ with 5 mol $\%$ are taken to compensate the loss of volatile elements ( $\mathrm{Bi}$ and $\mathrm{Na}$ ) during sintering $\mathrm{f}$ target and deposition process at high temperature. These powders grounded with $\mathrm{ZrO}_{2}$ balls in zirconia vessel by using high energy planetary ball mill (M/s Fritsch GmbH, Pulverisette 6, Germany) for 5h. The mixed slurry dried at $120^{\circ} \mathrm{C}$ for $24 \mathrm{~h}$ and further the fine powder calcined at $800{ }^{\circ} \mathrm{C}$ for $3 \mathrm{~h}$. The polyvinyl alcohol added as binder and pressed BNT target at the pressure of $400 \mathrm{MPa}$ by using $\mathrm{KBr}$ Press (M/s Technosearch Instruments, M-20, India) with 20mm diameter and $4 \mathrm{~mm}$ thickness, which is sintered at $1100{ }^{\circ} \mathrm{C}$ for $3 \mathrm{~h}$. The BNT films deposited on quartz and $\mathrm{Pt}(111) / \mathrm{Ti} / \mathrm{SiO}_{2} / \mathrm{Si}$ substrates by PLD for investing the optical and electrical properties respectively. During the film deposition, the deposition parameters such as $\mathrm{KrF}$ excimer laser (248 $\mathrm{nm}$ wavelength), pulse repetition rate $(5 \mathrm{~Hz})$, of pulse energy $(225 \mathrm{~mJ})$, target to substrate distance $(4 \mathrm{~cm})$ and laser fluence $\left(2 \mathrm{~J} / \mathrm{cm}^{2}\right)$ and substrate temperature $\left(700{ }^{\circ} \mathrm{C}\right)$ were kept at constant, whereas the oxygen partial pressure varied from 1 to $50 \mathrm{~Pa}$. As deposited $\mathrm{BNT} / \mathrm{Pt}(111) / \mathrm{Ti} / \mathrm{SiO}_{2} / \mathrm{Si}$ and $\mathrm{BNT} /$ quartz films were annealed under $\mathrm{O}_{2}$ atmosphere at $700{ }^{\circ} \mathrm{C}$ 
for $1 \mathrm{~h}$ to enhance the crystalline growth. To study electrical properties, $\mathrm{Al}$ is deposited on the film surface (Al/BNT/Pt(111)/Ti/SiO$/ 2 \mathrm{Si})$ as electrodes by thermal evaporator (M/s Hind High Vacuum, Lab Coater Auto 500, India).

The phase and crystal structure of BNT films were examined by X-ray diffractometer (M/s Rigaku, Japan, TTRAX III) with $\mathrm{Cu}-\mathrm{K}_{\alpha}$ radiation (1.5406 $\AA$ ). The scaling behavior and growth dynamics of the films were studied using surface morphology measurements performed by atomic force microscope (M/s Oxford, Cypher). The RT Raman spectra were recorded using the Raman spectrometer (M/s JOBIN YVON, LABRAM HR800) with an Ar-ion laser $(\lambda=514$ $\mathrm{nm})$. The transmittance spectra collected by UV-Vis-NIR spectrophotometer (M/s Shimadzu, UV 3101PC; Japan) to study the linear optical properties from Swanepoel envelop method. The frequency and temperature variation of dielectric properties were measured using LCR meter (M/s Wayne Kerr Electronics Pvt. Ltd, 1J43100) in the range of $100 \mathrm{~Hz}-1 \mathrm{MHz}$. The microwave dielectric properties of the thin films on quartz substrates were measured using a vector network analyzer (ZVA24; M/s Rohde \& Schwarz, Columbia, MD) by split post dielectric resonator (SPDR) method.

\section{Results and Discussions}

\subsection{XRD analysis}

Figure. 1(a-d) illustrates the X-ray diffraction (XRD) patterns of BNT thin films deposited on a quartz substrate at various oxygen $\left(\mathrm{O}_{2}\right)$ pressures from $1 \mathrm{~Pa}$ to $50 \mathrm{~Pa}$. The films deposited at lower and higher oxygen pressures exhibited BNT phase along with the secondary phase of $\mathrm{Bi}_{4} \mathrm{Ti}_{3} \mathrm{O}_{12}(\mathrm{BIT} 1)$ and $\mathrm{Bi}_{2} \mathrm{Ti}_{2} \mathrm{O}_{7}(\mathrm{BIT} 2)$. The secondary phases were suppressed with rise in the $\mathrm{O}_{2}$ pressure, and the single phase of BNT observed at $10 \mathrm{~Pa}$. The oxygen vacancies and interstitials oxygen ions creates charge fluctuations that leads the deviation of $\mathrm{Bi}, \mathrm{Na}$, and Ti ions stoichiometry in BNT. Hence, the secondary phases appeared in BNT thin films grown 
at lower and higher oxygen pressure. Zhao et al. [33] also observed similar defects in $\mathrm{BaTiO}_{3}$ thin films grown at lower oxygen pressure. Moreover, Debye-Scherrer's used to estimate the average crystallite size of deposited thin films at various pressures by the following equation [34].

$$
D=\frac{k \lambda}{\beta \cos \theta}
$$

where, $D$ is average crystallite size, $\beta$ is the full width at half maximum of diffraction peak (FWHM), $\theta$ is Bragg angle, $k$ is shape factor $(k=0.89)$, and $\lambda$ is the wavelength of $\mathrm{X}$-ray $(\mathrm{Cu}-$ $K_{\alpha}=1.5406 \AA$ ). The estimated average crystallite size is in the range of $17-25 \mathrm{~nm}$. The film deposited at lower oxygen pressure for $1 \mathrm{~Pa}$ having a smaller crystalline size of $17 \mathrm{~nm}$ and it increases to $25 \mathrm{~nm}$ up on increasing the oxygen pressure up to $50 \mathrm{~Pa}$. Oxygen partial pressure is one of the important parameter for the growth of oxide films grown by PLD, which can improve the film quality. It is well-known that the atomic kinetic energy affects the film crystallization and $P_{O 2}$ governs the atomic kinetic energy [35]. The atomic kinetic energy in plasma changes with rise in $P_{O 2}$ through the collisions with oxygen atoms. The target ablated species have large mean-free-path at lower oxygen pressure directly impinging on to the substrate surface. The adatoms on the surface are having maximum kinetic energy, since weak collisions between oxygen atoms and atoms in plasma. The maximum kinetic energy induces backscattering of adatoms, results in weak crystallization in the films. At higher/sufficient oxygen pressure, the atoms in the plasma plume could gain sufficient energy (i.e. smaller meanfree-path and lower kinetic energy) by scattering oxygen atoms, which prompts adatoms to reach thermodynamically stable locations through surface migration. The surface adatoms can migrate fast to look for lower energy sites and form low energy structure, which leads to improvement of the film crystallinity and quality. Hence, the film crystallinity improved with rise in $P_{O 2}$. Wang et al. [36] investigated that the vanadium oxide thin films grown at lower 
$P_{O 2}(0.008 \mathrm{~Pa})$ showed amorphous and the films become crystallized with rising the $P_{O 2}$. Yang et al. [37] also observed weak crystallization in $\mathrm{Ta}_{0.1} \mathrm{~W}_{0.9} \mathrm{O}_{\mathrm{x}}$ films at low $P_{O 2}$ caused by a large number of defects (oxygen vacancies), which prevent the film crystallization. Therefore, the oxygen pressure strongly influences crystallization, phase, orientation, nucleation, grain growth morphology, optical, and electrical properties of films.

\subsection{Scaling behavior and growth mechanism}

The surface morphology of BNT thin films was investigated by AFM which gives an insight of surface microstructure, scaling behavior, and growth dynamics of the films. The AFM 3D, 2D images, and their height profiles of BNT thin films deposited on quartz substrate at various oxygen partial pressures from $1 \mathrm{~Pa}$ to $50 \mathrm{~Pa}$ over a scan area of $5 \mu \mathrm{m} \times 5 \mu \mathrm{m}$ are shown in Figure 2. The AFM images are indicating the homogenous distribution of grains within the film surface. The root-means-square (RMS) surface roughness of the films is in the range of $8.6-11.2 \mathrm{~nm}$ estimated by WSxM 5.0 software. At lower pressure (1 Pa), the RMS roughness is $8.6 \mathrm{~nm}$ and is increased to $11.2 \mathrm{~nm}$ for the film deposited at $10 \mathrm{~Pa}$. Further, it is slightly decreased to $10.6 \mathrm{~nm}$ for the film deposited at $50 \mathrm{~Pa}$. The obtained RMS roughness of deposited films is in line with crystallite sizes.

In order to understand the dynamic scaling behavior and growth mechanism of films, the height-height correlation function (HHCF) is fitted with a suitable theoretical model to estimate the growth parameters: local roughness $\left(\alpha_{\mathrm{loc}}\right)$, RMS roughness (interface width) $(\omega)$ and lateral correlation length $(\xi)$ are calculated from AFM images using $\mathrm{HHCF}), \mathrm{H}(\mathrm{r}, \mathrm{t})$, which can describe the type of scaling and growth mechanism. It is a statistical average of the mean square of height difference between pair points $(\mathrm{x}, \mathrm{y})$ and $\left(\mathrm{x}^{\prime}, \mathrm{y}^{\prime}\right)$, separated by a distance $r$ is given by following equation $[31,38]$.

$$
H(r, t)=\left\langle\left|h\left(r+r^{\prime}, t\right)-h\left(r^{\prime}, t\right)\right|^{2}\right\rangle
$$


where, $h\left(r+r^{\prime}, t\right)$ and $h\left(r^{\prime}, t\right)$ is the heights of a surface at a point $(\mathrm{x}, \mathrm{y})$ and $\left(\mathrm{x}^{\prime}, \mathrm{y}^{\prime}\right)$. The HHCF can be estimated by spatial averaging over one or many regions of large extent, and it should be much larger than $r$ to avoid edge effects. It can also be defined by exponential correlation model satisfies the condition for self-affine surface and manifests anisotropic scale invariance by following equation [38].

$$
H(r)=2 \omega^{2}\left[1-\exp \left[-\left(\frac{r}{\xi}\right)^{2 \alpha}\right]\right]
$$

The HHCF exhibits two distinct behaviors depending on the relative magnitude of $\mathrm{r}$ and lateral correlation length $(\xi)$ as follows:

$$
\begin{gathered}
\text { For } r \ll \xi, \quad H(r<\xi)=2 \omega^{2}\left(\frac{r}{\xi}\right)^{2 \alpha} \\
\text { For } r \gg>\xi, \quad H(r>\xi)=2 \omega^{2}
\end{gathered}
$$

where, $\omega$ is the RMS roughness (interface width), $\alpha\left(0 \leq \alpha_{l o c} \leq 1\right)$ is the local roughness scaling exponent, which represents the short-range roughness of a self-affine surface and $\xi$ is the lateral correlation length. The log-log plot of HHCF versus distance $r$ along with fitted curve by Eqn (3) of BNT thin films for various oxygen partial pressures from $1 \mathrm{~Pa}-50 \mathrm{~Pa}$ is shown in Figure 3(a). The oscillatory behavior is observed for the film deposited higher pressures for $r \gg \xi$ signifying the formation of the mounded surface [30,38]. The H(r, t) is shifted upward as oxygen pressure $(P)$ increases with growth rate, which indicates the enhancement in RMS roughness. The $\alpha_{\mathrm{loc}}, \omega, \xi$ parameters are extracted from $\mathrm{HHCF}$ for the film deposited at different pressures to understand the scaling behavior and growth dynamics. The variation of $\alpha_{\mathrm{loc}}, \omega, \xi$ with $\mathrm{P}$ was shown in Figure 3(b), (c), and (d). The $\alpha_{\text {loc }}$ value of all the deposited films found to be $0.85 \pm 0.08$, which is in-between 0 and 1 . The smaller and larger value of $\alpha_{\text {loc }}$ indicates locally rough and locally smooth surface, respectively. The value of $\omega$ increases from $7.9-11.5 \mathrm{~nm}$ for the film grown at various pressure 
form $1-10 \mathrm{~Pa}$ confirm that the film is roughening during the growth process and is reduced (10.7 $\mathrm{nm})$ for the film deposited at high pressure $(50 \mathrm{~Pa})$. The high $\omega$ value because of the various nonlocal effects such as shadowing, high stickiness of substrate, bulk diffusion of incoming particles. The $\xi$ value is increased from 90 to $156 \mathrm{~nm}$ with the rise in $P_{O 2}$ from $1-10 \mathrm{~Pa}$ and beyond that, it decreases to $94 \mathrm{~nm}$ for $50 \mathrm{~Pa}$, which signifies the lateral growth of the islands varies with pressure. It indicates that as the pressure increases, the islands grow in both vertical and lateral, and the total film turn into rough. The lateral growth is due to the improvement in the nucleation of more incoming flux and the enhance in crystallite size with $P_{O 2}$. The sudden decrease in $\xi$ at higher pressure (50 Pa) might be due to appearance of the secondary phase can be seen in XRD results, where the film growth orientation shifts from (110) to (117). During nucleation and growth stage only vertical growth takes place while with an increase in oxygen pressure $(>10 \mathrm{~Pa})$, the vertical growth of the secondary phase dominates over the lateral growth and the RMS roughness slightly decreases as shown in Figure. 3(d) [39].

\subsection{Raman studies}

Figure 4(a) shows the Raman spectra of BNT films deposited on a quartz substrate at different $\mathrm{O}_{2}$ pressures measured from $50-1200 \mathrm{~cm}^{-1}$. BNT has 13 Raman active modes based on group theory: $\Gamma_{\text {Raman }}=4 \mathrm{~A}_{1}+9 \mathrm{E}$, where $\mathrm{A}_{1}$ and $\mathrm{E}$ modes are Raman and IR active [19]. The whole BNT Raman spectra can be categorised into four frequency regions (A, B, C and D) are shown in Figure 4(a). The Raman active $\mathrm{A}_{1}\left(\mathrm{TO}_{1}\right)$ modes located at $88.59-123.83 \mathrm{~cm}^{-1}$ are associated with the $\mathrm{Bi}-\mathrm{O}$ and $\mathrm{Na}-\mathrm{O}$ vibrations. The Raman active $\mathrm{E}\left(\mathrm{TO}_{2}\right)$ modes located at $159.66-409.63 \mathrm{~cm}^{-1}$ are associated with the Ti-O vibrations. The $\mathrm{TO}_{3}$ modes located at 481.94 $-637.10 \mathrm{~cm}^{-1}$ are associated with $\mathrm{TiO}_{6}$ octahedral vibrations. The $\mathrm{LO}_{3}$ modes located at 719.06 $-885.41 \mathrm{~cm}^{-1}$ are corresponding to the overlapping of $\mathrm{A}_{1}(\mathrm{LO})$ and $\mathrm{E}$ (LO) modes. In Figure 4(b), the $\mathrm{TO}_{1}, \mathrm{TO}_{2}$ and $\mathrm{TO}_{3}$ modes are shifted to the higher wavenumber, and the intensity of all the modes increased with increase in $P_{O 2}$ from $1-10 \mathrm{~Pa}$ which indicates improve in 
crystalline quality of films with $P_{O 2}$. In the case of a film deposited at $50 \mathrm{~Pa}$, all modes shifted to lower wavelength, whereas the BNT modes are suppressed due to the existence of secondary phase. However, the Raman spectrum of the film deposited at $10 \mathrm{~Pa}$ is similar to that of the BNT target and earlier reports $[15,40]$.

\subsection{Optical properties}

Figure 5(a) shows the optical transmittance spectra of BNT thin films deposited on quartz substrates at various $\mathrm{O}_{2}$ partial pressures in the wavelength range of 200 to $2500 \mathrm{~nm}$. The oscillations in the spectra due to multiple reflections between air to film and film to substrate interfaces. The spectra of all the films found to be 50 to $85 \%$ of transmission in the visible region, which is relatively high transmittance confirm the low surface roughness and better homogeneity of films. A sharp drop in optical transmission at the wavelength of $300-400 \mathrm{~nm}$ region corresponds to strong absorption, which is the fundamental absorption of the film. It can be seen that the transmittance of deposited films is decreased, where the transmittance spectra shifted to higher wavelength in the absorption region with increasing oxygen pressure. The thickness $(t)$ and refractive index $\left(n_{f}\right)$ of the thin films for different $\mathrm{O}_{2}$ pressures calculated using Swanepoel's envelope method by following equations [41].

$$
\begin{aligned}
n_{f} & =\left[N+\left(N^{2}-n_{s}^{2}\right)^{0.5}\right]^{0.5} \\
N & =2 n_{S}^{2}\left(\frac{T_{\max }-T_{\min }}{T_{\max } T_{\min }}\right)+\frac{n_{S}^{2}+1}{2} \\
t & =\frac{\lambda_{1} \lambda_{2}}{4\left(\lambda_{1} n_{2}-\lambda_{2} n_{1}\right)}
\end{aligned}
$$

where, $n_{s}$ is the substrate refractive index, $T_{\max }$ and $T_{\min }$ are transmission maximum and minimum at a certain wavelength $(\lambda), n_{1}$ and $n_{2}$ are refractive indices at two adjacent maximum or minimum at $\lambda_{1}$ and $\lambda_{2}$. The estimated $t, n_{f}$, and absorption coefficient $(\alpha)$ values are shown in Figure 5 (b and c). The $t$ and $n_{f}$ values are found to be increased from 1067, 1091, and 1349 
$\mathrm{nm}$ and $1.83,1.90$, and 2.31 with the rise in the $\mathrm{O}_{2}$ pressure from 1,5 and $10 \mathrm{~Pa}$. The increase in thickness with oxygen pressure is due to the confinement of plasma, which leads to an increase in the particle flux. Consequently, a higher deposition rate. The thickness of the film deposited at $50 \mathrm{~Pa}, \mathrm{O}_{2}$ pressure is very thick, producing over confinement of the plasma, which limiting the incoming flux impinging on the substrate and hence, the decrease in film thickness [42]. Further, the optical packing density $\left(P_{0}\right)$ of thin films is calculated by the following expression.

$$
P_{0}=\left(\frac{n_{f}^{2}-1}{n_{f}^{2}+2}\right)\left(\frac{n_{b}^{2}+2}{n_{b}^{2}-1}\right)
$$

where, $n_{b}$ is the refractive index of the bulk BNT (2.32) [43]. The estimated optical packing density lies in the range of $73.94-99.52 \%$ and is increased with $\mathrm{O}_{2}$ pressure as shown in Figure 5 (c). The improvement in crystallinity, optical packing density, decrease in oxygen vacancies and change in the phase could be the reason for larger $n_{f}$ and $k$ values at film deposited for $10 \mathrm{~Pa}$.

The optical bandgap energy $\left(E_{g}\right)$ of BNT thin films can be calculated using Tauc relation in strong absorption region for direct bandgap by following expression [44].

$$
(\alpha h v)^{2}=A\left(h v-E_{g}\right)
$$

Where, $A$ is a constant, and $h v$ is the photon energy. The Tauc plot: $h v$ vs. $(\alpha h v)^{2}$ is shown in Figure 5(b). The intersection of the tangent line with $\mathrm{X}$-axis provides the bandgap of films are shown in Figure 5 (c). The $E_{g}$ values are slightly decreased from 3.55 to $3.34 \mathrm{eV}$ with the rise in $\mathrm{O}_{2}$ pressure from 1 to $50 \mathrm{~Pa}$ due to the improvement in crystallinity and reduction in the oxygen vacancies in the films which turn in narrowing bandgap. The obtained bandgap energy values of BNT thin films are close to the reported values deposited by similar PLD technique $[43,45]$.

\subsection{Dielectric and microwave dielectric properties}


The frequency variation of dielectric constant $\left(\varepsilon_{r}\right)$ and dielectric loss $(\tan \delta)$ of BNT thin films deposited at various $\mathrm{O}_{2}$ pressures and measured at RT are shown in Figure 6(a-b). The $\varepsilon_{r}$ values decrease with increase in frequency due to a decrease in the net polarization in the films, i.e., frequency dispersion behavior. The $\varepsilon_{\mathrm{r}}$ and $\tan \delta$ values of deposited films are in the range of $295-454$ and $1.13-0.140 @ 1 \mathrm{kHz}$, respectively. The $\varepsilon_{r}$ values of BNT thin films enhanced and $\tan \delta$ values decreased with an increase in $\mathrm{O}_{2}$ pressure from 1 to $10 \mathrm{~Pa}$ as shown in Figure 6(c). The film deposited at $10 \mathrm{~Pa}$ exhibited the higher $\varepsilon_{r}(454)$ and lower $\tan \delta(0.140)$ at $1 \mathrm{kHz}$. The improvement in the dielectric properties is observed with an increase in the pressure due to reduction in oxygen vacancies, conductivity, improvement in the crystallinity as well as the stabilization of BNT phase. Further, the obtained single-phase BNT thin films deposited at 10 $\mathrm{Pa}$ are carried out to study the temperature variation of $\varepsilon_{r}$ and $\tan \delta$ at different frequencies from $1-100 \mathrm{kHz}$ is shown in Figure 6(d). The $\varepsilon_{r}$ and $\tan \delta$ values are found to be decreased with an increase in frequency with temperature. It also revealed the two structural phase transitions: (i) ferro to anti-ferro transition, which corresponds to rhombohedral to tetragonal transition, i.e., depolarization transition temperature $\left(T_{\mathrm{d}} \sim 225{ }^{\circ} \mathrm{C}\right)$ and (ii) anti-Ferro to para transition corresponds to tetragonal to cubic transition, which is called as Curie transition temperature $\left(T_{\mathrm{C}} \sim 296^{\circ} \mathrm{C}\right)$. These results are similar to that of bulk BNT ceramics and are in good agreement with the previous reports $[19,46]$.

The microwave dielectric properties of BNT thin films deposited on quartz substrates at various oxygen pressures are investigated by SPDR technique [47]. The SPDR is a familiar, non-destructive, and accurate technique for measuring the microwave dielectric permittivity and loss tangent of thin films at a spot frequency in the microwave region of 5 and $10 \mathrm{GHz}$. The dielectric resonators use a specific resonant mode with a specific resonant frequency, which depends on the SPDR permittivity and its dimensions. The electric field in the SPDR film is parallel to the interface of film. Resonators can operate different modes, and the $\mathrm{TE}_{01 \delta}$ 
mode is preferable, which has an azimuthal electric field component. Accordingly, the electric field remains continuous on the test interfaces and is insensitive to the presence of air gaps perpendicular to the z-axis of the fixture [47]. The microwave dielectric permittivity and loss tangent of substrate and film depend on resonant frequency and quality factor. Figure 7(a) shows the resonance spectra of the substrate and BNT thin film (10 Pa) measured at $5 \mathrm{GHz}$. The resonant frequency and quality factor of the empty resonator $\left(f_{01}, Q_{01}\right)$ and resonant frequency and quality factor of the substrate $\left(\mathrm{f}_{0}, \mathrm{Q}_{0}\right)$ is measured as shown in Figure $7(\mathrm{c})$. There is a shift in resonant frequency when the thin film placed in SPDR. The shift of resonant frequency and its quality factor $\left(\mathrm{f}_{\mathrm{s}}, \mathrm{Q}_{\mathrm{s}}\right)$ of the film is measured and is shown in Figure 7(b). The resonant frequency, unloaded Q-factor and other parameters are estimated by using the Rayleigh-Ritz method. The real part of dielectric permittivity and loss tangent of deposited films are determined from the measured resonant frequency, quality factor and film thickness by equation 16 and 17.

$$
\begin{aligned}
& \varepsilon_{r}=1+\frac{\left(f_{0}-f_{s}\right)}{h f_{0} k_{s}\left(\varepsilon_{r}, h\right)} \\
& \tan \delta=\frac{Q^{-1}-Q_{D r}^{-1}-Q_{c}^{-1}}{P_{e s}}
\end{aligned}
$$

where, $h$ is the thickness of the film, $f_{0}$ and $f s$ is the resonance frequency of the substrate (quartz) and film (BNT), $K_{s}$ is a function of $\varepsilon_{r}$ and $h . Q$ is an unloaded quality factor of resonator having the thin film, $Q_{D r}$ is dielectric losses in the resonator, $Q_{c}$ is losses of metallic for a resonant cavity having thin film and Pes is the electrical energy filling factor of the film $[47,48]$.

The estimated $\varepsilon_{r}$ and $\tan \delta$ of deposited thin films at various pressures are displayed in Table 1. The $\varepsilon_{r}$ values of BNT thin films gradually improved with the rise in the $\mathrm{O}_{2}$ pressure from $1 \mathrm{~Pa}$ to $10 \mathrm{~Pa}$. It is due to an increase in the optical packing density, crystallinity, refractive index, and stabilization pf BNT phase with $\mathrm{O}_{2}$ partial pressure. It is also observed that the $\varepsilon_{r}$ 
values of BNT thin films decreased with a rise in the frequency from $5 \mathrm{GHz}$ to $10 \mathrm{GHz}$ due to decrease in polarization and increase in conductivity. The loss tangent of thin films deposited at lower $\mathrm{O}_{2}$ pressure exhibited slightly high than higher pressure due to the presence of $\mathrm{O}_{2}$ deficiencies. The loss is found to be decreased with rising in $\mathrm{O}_{2}$ pressure. The improvement in microwave dielectric properties of BNT thin films is obtained due to the minimization of oxygen vacancies. The higher $\varepsilon_{r}$ (336 and 264) and low $\tan \delta(0.0093$ and 0.0015$)$ values are obtained at 5, and $10 \mathrm{GHz}$ frequencies for the film deposited at $10 \mathrm{~Pa}$ pressure is promising for the applications of tunable microwave and high-frequency devices.

\section{Conclusions}

In oxides materials, oxygen content is one of the critical parameter which plays an important role in controlling the stoichiometry and crystalline quality of thin films for investigating the structural and physical properties. In this work, the influence of $\mathrm{O}_{2}$ partial pressure on structural, surface morphological, optical, and microwave dielectric properties of BNT thin films are presented in detail. The single phase of BNT films obtained at film deposited@10 Pa, is confirmed from XRD and Raman spectroscopic studies. The local roughness exponent, $\alpha_{\mathrm{loc}}(0.85 \pm 0.08)$ is larger which corresponds to the locally smooth surface. The interface width $(\omega)$, and lateral correlation length $(\xi)$ increases with pressure indicate roughening and islands grow in lateral and vertical directions during the growth process. The optical and microwave dielectric properties of BNT films are significantly improved with $\mathrm{O}_{2}$ pressure due to the reduction in oxygen deficiencies and improvement in crystallinity. The BNT thin films exhibited two structural phase transitions from ferro to anti-ferro transition $\left(T_{\mathrm{d}} \sim 225^{\circ} \mathrm{C}\right)$ and anti-Ferro to para transition $\left(T_{\mathrm{C}} \sim 296^{\circ} \mathrm{C}\right)$. The higher $\varepsilon_{r}(336$ and 264$)$ and low $\tan \delta(0.0093$ and 0.0015 ) values are observed at 5 , and $10 \mathrm{GHz}$ frequencies for the film deposited at $10 \mathrm{~Pa}$ pressure and is suitable for the applications in high-frequency devices. 


\section{Acknowledgments}

The work was financially supported by DAE BRNS [37(1)/14/33/2015/BRNS], India. The authors grateful to Centre for Nanotechnology and Central Instruments Facility (CIF), Indian Institute of Technology Guwahati, India for providing experimental facilities.

\section{References}

1. S. Takagi, A. Subedi, V. R. Cooper, and D. J. Singh, Phys. Rev. B - Condens. Matter Mater. Phys. 82, 19 (2010).

2. J. F. Scott, Science (80-. ). 315, 954 (2007).

3. N. D. Co, L. V. Cuong, B. D. Tu, P. D. Thang, L. X. Dien, V. N. Hung, and N. D. Quan, J. Sci. Adv. Mater. Devices (2019).

4. M. S. Tsai, S. C. Sun, and T. Y. Tseng, J. Appl. Phys. 82, 3482 (1997).

5. Z. Kutnjak, R. Blinc, and Y. Ishibashi, Phys. Rev. B - Condens. Matter Mater. Phys. 76, 104102 (2007).

6. Y. Saito, H. Takao, T. Tani, T. Nonoyama, K. Takatori, T. Homma, T. Nagaya, and M. Nakamura, Nature 432, 84 (2004).

7. F. Li, D. Lin, Z. Chen, Z. Cheng, J. Wang, C. Li, Z. Xu, Q. Huang, X. Liao, L. Q. Chen, T. R. Shrout, and S. Zhang, Nat. Mater. 17, 349 (2018).

8. Q. Wang, C. R. Bowen, W. Lei, H. Zhang, B. Xie, S. Qiu, M. Y. Li, and S. Jiang, J. Mater. Chem. A 6, 5040 (2018).

9. G. gui Peng, D. yi Zheng, C. Cheng, J. Zhang, and H. Zhang, J. Alloys Compd. 693, 1250 
(2017).

10. A. M. Mazuera, P. S. Silva, A. D. Rodrigues, P. S. Pizani, Y. Romaguera-Barcelay, M. Venet, and M. Algueró, Phys. Rev. B 94, 1 (2016).

11. B. Dai, P. Zheng, W. Bai, F. Wen, L. Li, W. Wu, Z. Ying, and L. Zheng, J. Eur. Ceram. Soc. 38, 4212 (2018).

12. H. Bao, C. Zhou, D. Xue, J. Gao, and X. Ren, J. Phys. D. Appl. Phys. 43, (2010).

13. D. Shreiber, W. Zhou, G. Dang, M. Taysing-Lara, G. Metcalfe, E. Ngo, M. Ivill, S. G. Hirsch, and M. W. Cole, Thin Solid Films 660, 282 (2018).

14. X. X. Wang, X. G. Tang, and H. L. W. Chan, Appl. Phys. Lett. 85, 91 (2004).

15. S. Pattipaka, A. R. James, and P. Dobbidi, J. Electron. Mater. 47, 3876 (2018).

16. M. Peddigari and P. Dobbidi, AIP Adv. 5, 0 (2015).

17. G. A. Smolenskii, V. A. Isupov, A. I. Agranovskaya, and N. N. Krainik, Fiz. Tverd. Tela Sanktpeterbg. 2, 2982 (1960).

18. M. Matsuura, H. Iida, K. Hirota, K. Ohwada, Y. Noguchi, and M. Miyayama, Phys. Rev. B - Condens. Matter Mater. Phys. 87, 22 (2013).

19. S. Pattipaka, A. R. James, and P. Dobbidi, J. Alloys Compd. 765, 1195 (2018).

20. C. Peng, J. F. Li, and W. Gong, Mater. Lett. 59, 1576 (2005).

21. M. Li, M. J. Pietrowski, R. A. De Souza, H. Zhang, I. M. Reaney, S. N. Cook, J. A. Kilner, and D. C. Sinclair, Nat. Mater. 13, 31 (2014).

22. Y. Yao, Y. Li, N. Sun, J. Du, X. Li, L. Zhang, Q. Zhang, and X. Hao, J. Alloys Compd. 750, 228 (2018). 
23. J. Cui, Y. Zhang, J. Wang, Z. Zhao, H. Huang, W. Zou, M. Yang, R. Peng, W. Yan, Q. Huang, Z. Fu, and Y. Lu, Phys. Rev. B 100, 165312 (2019).

24. M. N. R. Ashfold, F. Claeyssens, G. M. Fuge, and S. J. Henley, Chem. Soc. Rev. 33, 23 (2004).

25. H. Fujioka, in Handb. Cryst. Growth Thin Film. Ep. Second Ed. (2014), pp. 365-397.

26. S. Zorba, L. Yan, N. J. Watkins, and Y. Gao, Appl. Phys. Lett. 81, 5195 (2002).

27. B. C. Mohanty, H. R. Choi, and Y. S. Cho, J. Appl. Phys. 106, (2009).

28. S. Yim and T. S. Jones, Phys. Rev. B - Condens. Matter Mater. Phys. (2006).

29. S. Das Sarma, P. P. Chatraphorn, and Z. Toroczkai, Phys. Rev. B - Condens. Matter Mater. Phys. 64, 2054071 (2001).

30. R. Kesarwani, P. P. Dey, and A. Khare, RSC Adv. 9, 7967 (2019).

31. G. Pradhan, P. P. Dey, and A. K. Sharma, RSC Adv. 9, 12895 (2019).

32. N. Rotenberg, A. D. Bristow, M. Pfeiffer, M. Betz, and H. M. Van Driel, Phys. Rev. B Condens. Matter Mater. Phys. 75, 1 (2007).

33. T. Zhao, Z. H. Chen, F. Chen, H. Bin Lu, G. Z. Yang, and H. S. Cheng, Appl. Phys. Lett. 77, 4338 (2000).

34. V. Kumar, C. S. S. Sandeep, R. Philip, V. Kumar, and C. S. S. Sandeep, 98, 661 (2011).

35. Z. G. Zhang, F. Zhou, X. Q. Wei, M. Liu, G. Sun, C. S. Chen, C. S. Xue, H. Z. Zhuang, and B. Y. Man, Phys. E Low-Dimensional Syst. Nanostructures 39, 253 (2007).

36. Y. L. Wang, X. K. Chen, M. C. Li, R. Wang, G. Wu, J. P. Yang, W. H. Han, S. Z. Cao, and L. C. Zhao, Surf. Coatings Technol. 201, 5344 (2007). 
37. D. Yang and L. Xue, Thin Solid Films 494, 28 (2006).

38. Evolution of Thin Film Morphology (2008).

39. K. Chopra and J. Klerrer, Thin Film Phenomena (McGraw-Hill, New York; London, 1970).

40. F. Yang, P. Wu, and D. C. Sinclair, J. Mater. Chem. C 5, 7243 (2017).

41. R. Swanepoel, J. Phys. E. 16, 1214 (1983).

42. A. T. T. Mostako and A. Khare, Laser Part. Beams 30, 559 (2012).

43. M. Bousquet, J. R. Ducl̀re, E. Orhan, A. Boulle, C. Bachelet, and C. Champeaux, J. Appl. Phys. 107, (2010).

44. J. Tauc, Opt. Prop. Solids 277 (1972).

45. A. Joseph, J. P. Goud, S. R. Emani, and K. C. J. Raju, AIP Conf. Proc. 1731, 80039 (2016).

46. Y. Zhao, X. Hao, and M. Li, J. Alloys Compd. 601, 112 (2014).

47. J. Krupka, J. Eur. Ceram. Soc. 23, 2607 (2003).

48. J. Krupka, A. P. Gregory, O. C. Rochard, R. N. Clarke, B. Riddle, and J. Baker-Jarvis, J. Eur. Ceram. Soc. 21, 2673 (2001). 


\section{List of Tables:}

Table 1: Microwave dielectric properties of $\mathrm{BNT}$ films deposited at various $\mathrm{O}_{2}$ pressures.

\begin{tabular}{ccccc}
\hline \multirow{2}{*}{ O2 Pressure } & \multicolumn{2}{c}{$\mathbf{5 ~ G H z}$} & \multicolumn{2}{c}{$\mathbf{1 0 ~ G H z}$} \\
\cline { 2 - 5 }$(\mathbf{P a})$ & $\varepsilon_{r}$ & $\tan \boldsymbol{\delta}$ & $\varepsilon_{r}$ & $\tan \boldsymbol{\delta}$ \\
\hline $\mathbf{1}$ & 281 & 0.0028 & 255 & 0.0063 \\
$\mathbf{5}$ & 326 & 0.0013 & 258 & 0.0036 \\
$\mathbf{1 0}$ & 336 & 0.0093 & 264 & 0.0154 \\
$\mathbf{5 0}$ & 263 & 0.0083 & 241 & 0.0038 \\
\hline
\end{tabular}

\section{List of figure captions:}

Figure 1: XRD pattern of BNT films deposited at various oxygen partial pressures at (a) $1 \mathrm{~Pa}$ (b) $5 \mathrm{~Pa}$, (c) $10 \mathrm{~Pa}$ and (d) $50 \mathrm{~Pa}$.

Figure 2: AFM 3D (left side) and 2D (centre) images of BNT films for (a) $1 \mathrm{~Pa}$ (b) $5 \mathrm{~Pa}$, (c) $10 \mathrm{~Pa}$ and (d) $50 \mathrm{~Pa}$. Height profile of each image is shown at the right side of respective images.

Figure 3: (a) log-log plot of HHCF, $H(r)$ as a function of distance $r$ with fitted theoretical curve for BNT thin films at various pressures from $1-50 \mathrm{~Pa}$. The plot of (b) roughness exponent $\alpha_{\mathrm{loc}},(\mathrm{c})$ surface roughness $\omega$ and (d) correlation length $\xi$ as a function of pressure $(P)$.

Figure 4: (a) Raman spectra and (b) Wavenumber versus oxygen partial pressure of BNT films, deposited at $1 \mathrm{~Pa}, 5 \mathrm{~Pa}, 10 \mathrm{~Pa}$ and $50 \mathrm{~Pa}$. 
Figure 5: (a) Optical transmittance spectra, inset of Figure 5.5(a) optical bandgap energy of BNT films deposited at various pressures. (b-c) $t, \alpha, n, P_{0}$, and $E_{g}$ values as a function of oxygen pressure.

Figure 6: (a) and (b) The frequency variation of (a) $\varepsilon_{r}$ and (b) $\tan \delta$ of BNT films deposited under various pressures measured at RT. (c) The $\varepsilon_{r}$ and $\tan \delta$ values as a function of $\mathrm{O}_{2}$ pressure. (d) The temperature variation of $\varepsilon_{r}$ and $\tan \delta$ of BNT films deposited at 10 Pa pressure measured at different frequencies.

Figure 7: (a) Resonance curve of Split Post Dielectric Resonator of nominal frequency $5 \mathrm{GHz}$ with the investigated substrate (quartz) and film (10 Pa). (b) and (c) are the magnified image of Figure 14(a) for BNT film and substrate, respectively. 
Figures

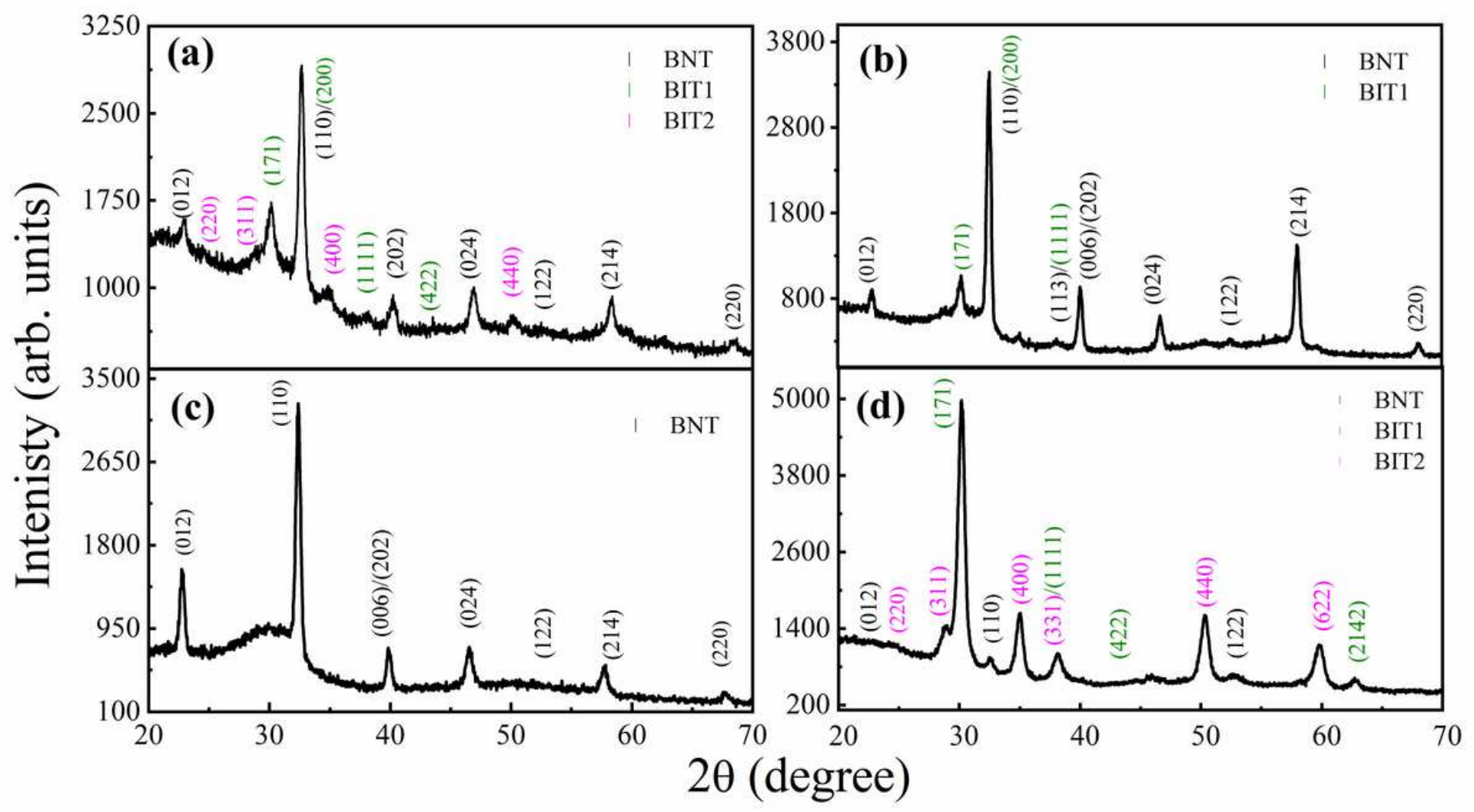

Figure 1

XRD pattern of BNT films deposited at various oxygen partial pressures at (a) $1 \mathrm{~Pa}$ (b) $5 \mathrm{~Pa}$, (c) $10 \mathrm{~Pa}$ and (d) $50 \mathrm{~Pa}$. 


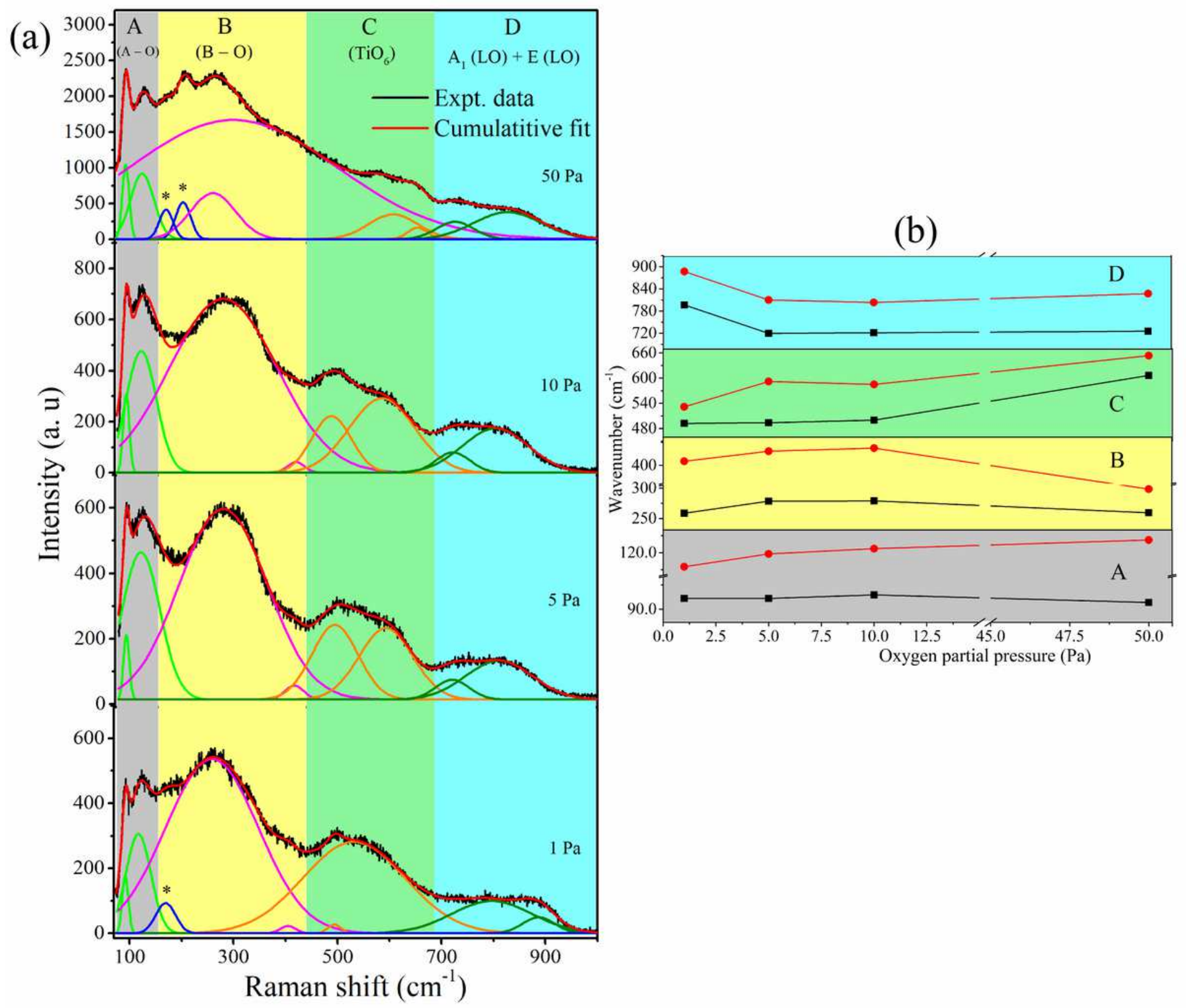

Figure 2

AFM 3D (left side) and 2D (centre) images of BNT films for (a) $1 \mathrm{~Pa}$ (b) $5 \mathrm{~Pa}$, (c) $10 \mathrm{~Pa}$ and (d) $50 \mathrm{~Pa}$. Height profile of each image is shown at the right side of respective images. 


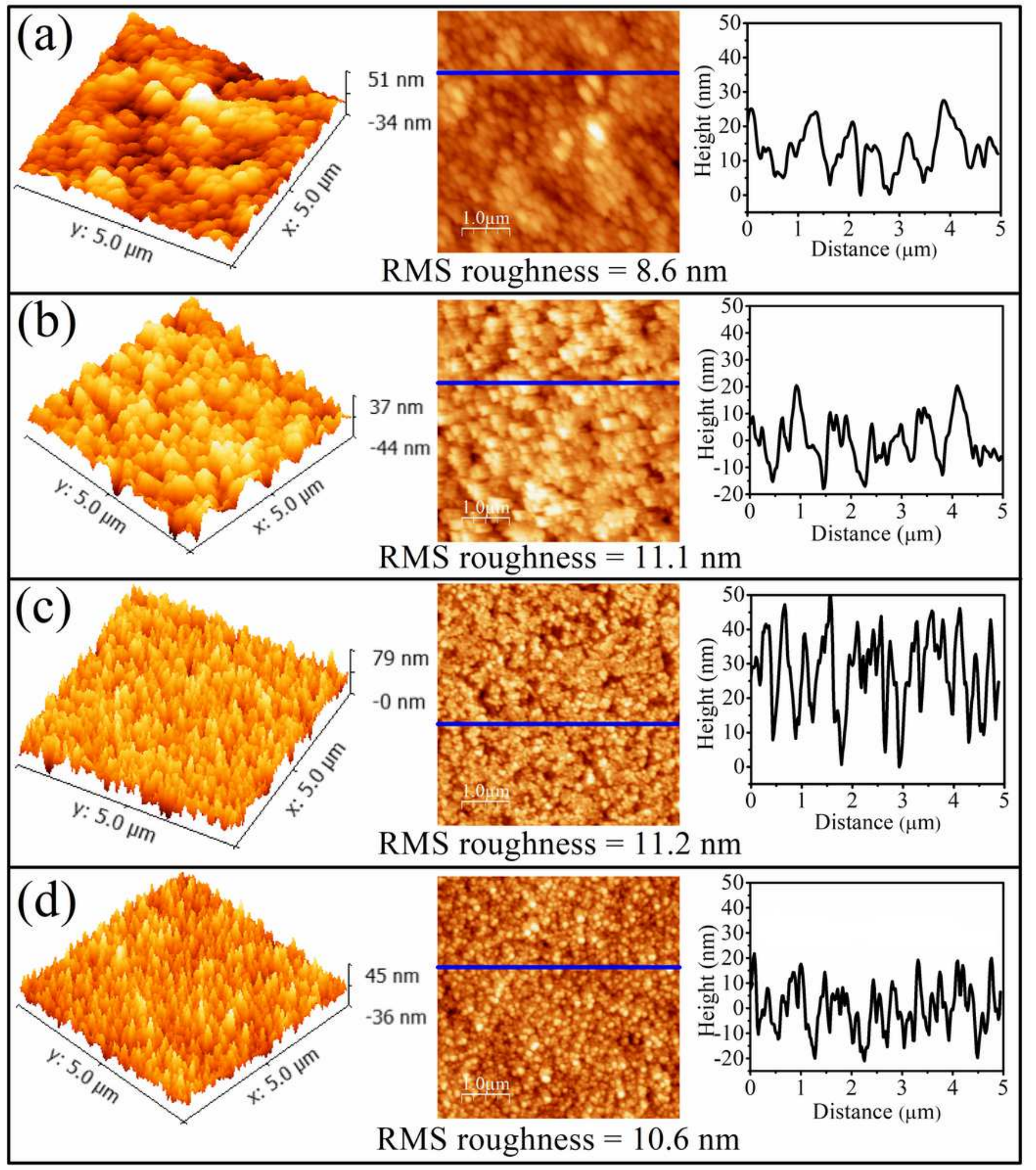

Figure 3

(a) log-log plot of HHCF, $\mathrm{H}(\mathrm{r})$ as a function of distance $r$ with fitted theoretical curve for BNT thin films at

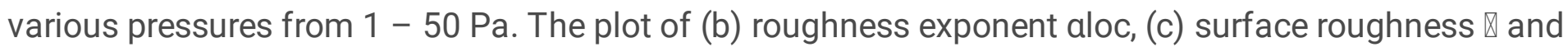
(d) correlation length $\xi$ as a function of pressure $(P)$ 

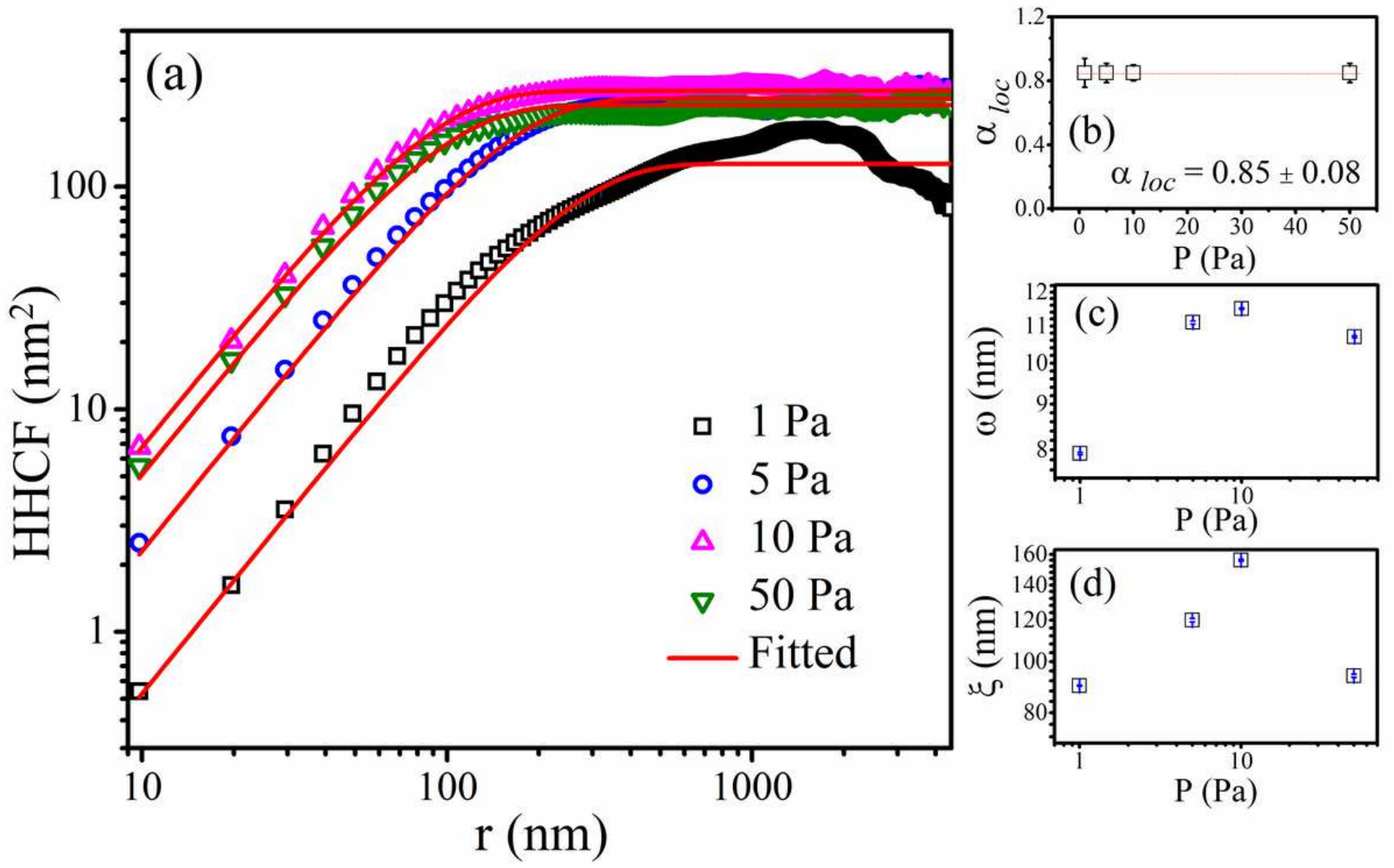

Figure 4

(a) Raman spectra and (b) Wavenumber versus oxygen partial pressure of BNT films, deposited at $1 \mathrm{~Pa}, 5$ $\mathrm{Pa}, 10 \mathrm{~Pa}$ and $50 \mathrm{~Pa}$.
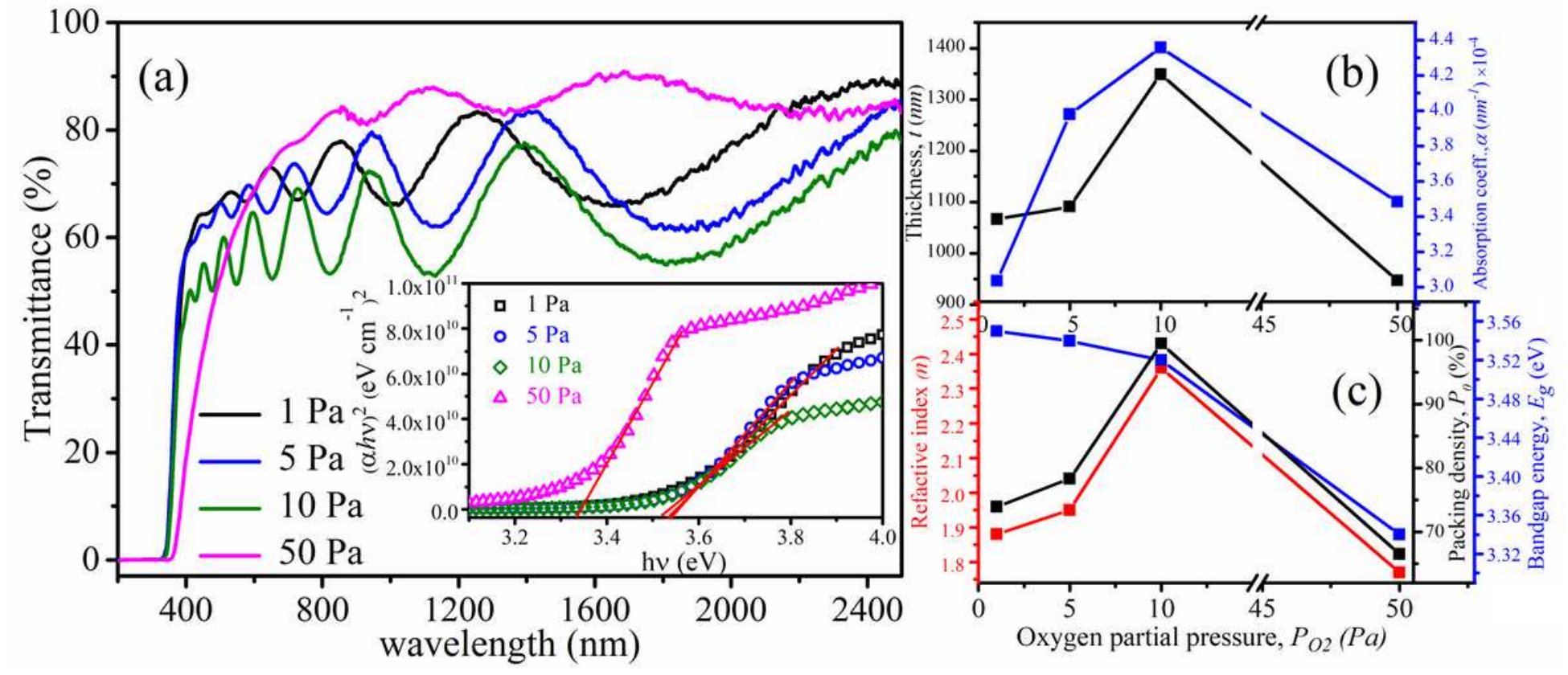

Figure 5 
(a) Optical transmittance spectra, inset of Figure 5.5(a) optical bandgap energy of BNT films deposited at various pressures. (b-c) t, a, n, P0, and Eg values as a function of oxygen pressure.
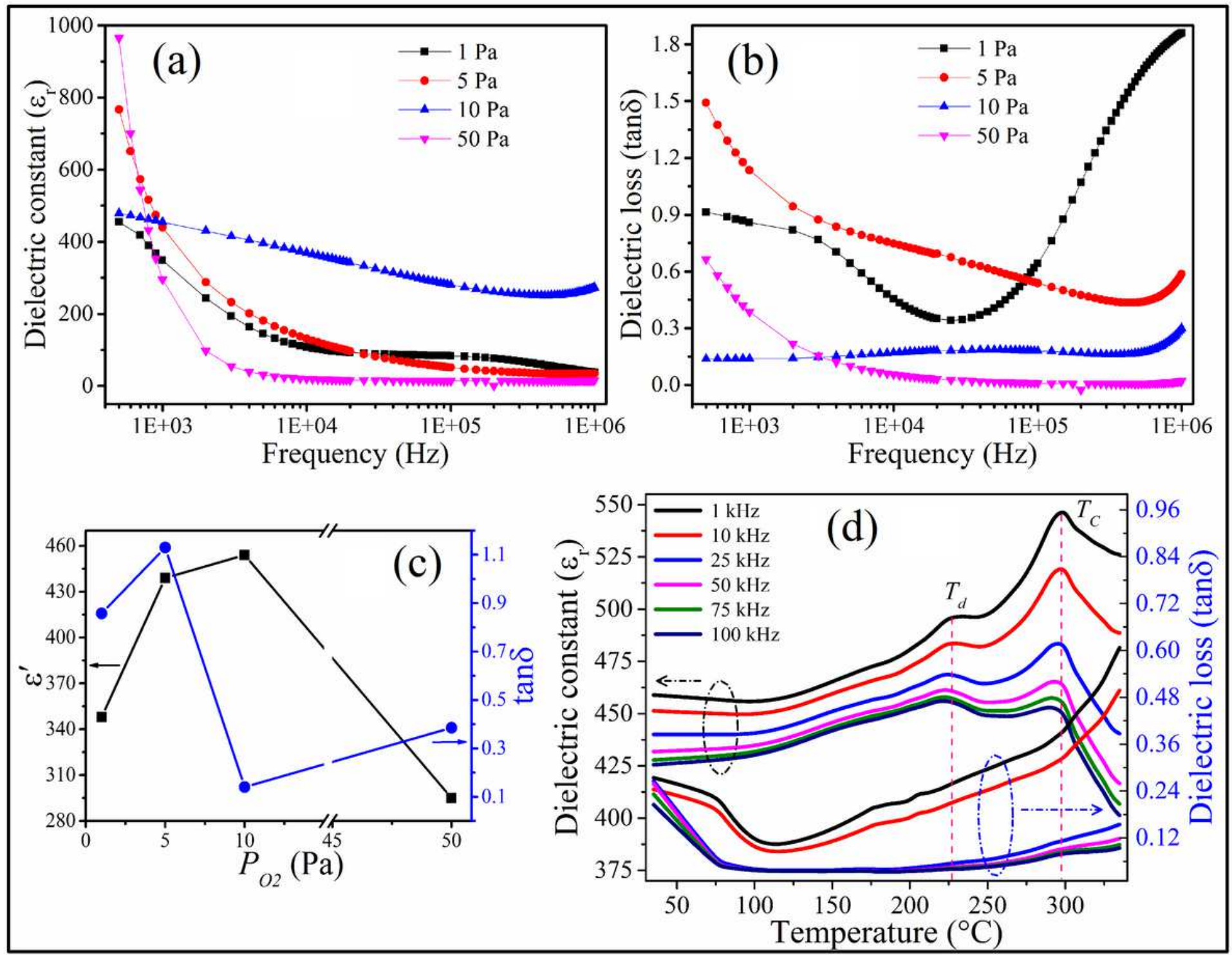

Figure 6

(a) and (b) The frequency variation of (a) $\varepsilon r$ and (b) $\tan \bigotimes$ of BNT films deposited under various pressures measured at RT. (c) The $\varepsilon r$ and tan $\Downarrow$ values as a function of 02 pressure. (d) The temperature variation of $\varepsilon r$ and $\tan \otimes$ of BNT films deposited at 10 Pa pressure measured at different frequencies. 

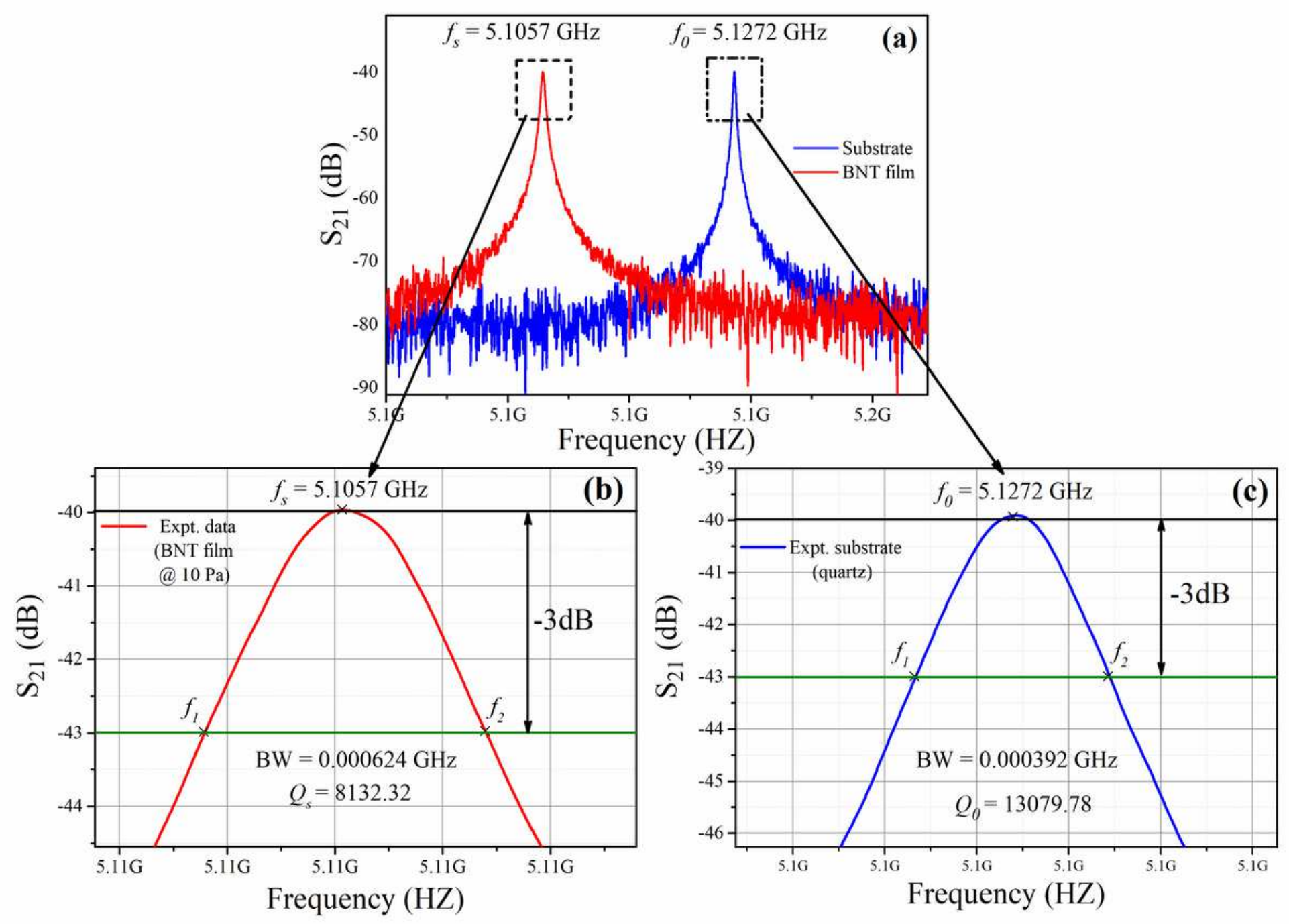

Figure 7

(a) Resonance curve of Split Post Dielectric Resonator of nominal frequency $5 \mathrm{GHz}$ with the investigated substrate (quartz) and film (10 Pa). (b) and (c) are the magnified image of Figure 14(a) for BNT film and substrate, respectively 